\title{
The Spatial Concomitance of Former Bantu Universities with Uneven Regional Development in a Democratic South Africa
}

\author{
Professor Johannes Tsheola \\ Department of Development Planning \& Management, University of Limpopo \\ P.O. Box 313, Fauna Park, 0787, South Africa \\ johannes.tsheola@ul.ac.za
}

\section{Doi:10.5901/mjss.2014.v5n20p863}

\section{Abstract}

The salience of universities in regional development has increased with the ascendancy of corporatization of public utilities, especially given the pre-eminence of the notion that these institutions create and enforce "learning regions" wherein knowledge generated is used for the enhancement of economic productivity and innovativeness. Under South Africa's state capitalism, most state-backed corporations have literally gobbled public funds, insisted on increased autonomy and behaved like private multinational companies, whilst their regional development impacts remained inconclusive. A reasonable geographic perspective should hold that, notwithstanding the effects of globalization, universities' regional development impacts are strongly "attenuated over space and distance". In this context, a democratic South Africa's restructuring of the higher education system should raise vexed questions of the regional development impacts of the former Bantu Universities. Given the significance of knowledge and research to regional development, this article concludes that Limpopo and Eastern Cape Province as well as Northern Cape and Mpumalanga Province, which are in the process of establishing their first universities, will continue to lag behind Western Cape, Gauteng, KwaZulu-Natal, Free State and North West Province. It argues that the heightened public financial support to former Bantu Universities will remain a public opportunity-cost because these institutions' orientation, as per their apartheid spatial-fix, is not amenable to the establishment of "learning regions". The article concludes that under state capitalism former Bantu Universities are denied their traditional contributions to the viability of informal businesses, simultaneously as their potential capacity to create and enforce "learning regions" remains virtually non-existent. Given the spatial-fix of the racially-inspired higher education landscape, the article concedes that corporatization of public utilities under democracy needs to be supplemented by deliberate state effort to build knowledge transfer networks with local and extra-local universities in a structure that deliberately embeds the less favoured regions and foster the spirit of innovation therein.

Keywords: Former Bantu Universities; Regional Development; Public Utilities; South Africa

\section{Introduction}

The ascendency of marketization and liberalization has motivated many local governments in the world to "promote the local economies through technology transfer and innovation" (Hong, 2008, p.589). As modern growth theory stresses the importance of human capital in innovation, economic productivity and development (Fedderke, de Kadt and Luiz, 2003, p.377), higher education institutions came to be "regarded as the "engine of development in the new world economy"' (Castells, 1994, p.14 cited in Tilak, 2011, p.4) wherein their inputs and outputs involve a specialised form of human capital. With the transition of the economic context from craft production, industrial mass production to post-industrial knowledge-driven economies, higher education and research institutions, particularly universities, too had to evolve from being storehouses of knowledge through knowledge factories to knowledge hubs (Shapira and Youtie, 2004; Youtie and Shapira, 2008; Bramwell and Wolfe, 2008; Knievel and Sheridan-Rabideau, 2009; Marginson, 2010). According to Marginson (2010, p.6979) "higher education and research carry much of the future potential of humanity and their benefits are maximized when they flow freely across the world". Paradoxically, corporatization, privatization and commercialization have equally marked a shift in "jurisdiction power of universities from central to local control"; and, they are expected to strengthen these institutions' "connections with local governments and local industries" (Hong, 2008, p.593). However, "lived" experiences from Europe and China have conclusively demonstrated that marketization and transition from the Keynesian welfare state to neoliberalism is associated with uneven regional development and increasing inequality (Hong, 2008; Bramwell and Wolfe, 2008; Knievel and Sheridan-Rabideau, 2009). But the relationship of universities and regional development is more complex and reciprocal.

The theoretical template for evaluation of the Bantu Universities' evolution from storehouse of knowledge to 
knowledge hubs and the capacity to create learning regions may as well be premature because the system of higher education in sub-Saharan Africa is itself "a young and nascent phenomenon" which has remained weakly established (Teferra, 2005, p.153 cited in Tilak, 2011, p.5). But South Africa.info (2014, n.p.) reports that "Many of South Africa's universities are world-class academic institutions at the cutting edge of research in various spheres". To be precise, these world-class institutions are the best ten South African universities of North West, University of Johannesburg, University of the Western Cape, Rhodes University, University of South Africa, University of KwaZulu-Natal, University of the Witwatersrand, University of Pretoria, University of Cape Town and Stellenbosch University, in ascending order (Answers Africa, 2014). Whereas university rankings are variable and contestable, there is convergence on the notion that the five that are in the top 100 universities of the emerging economies, viz. University of Cape Town (3), Witwatersrand (15), Stellenbosch (21), KwaZulu-Natal (45) and Pretoria (78) are South Africa's best (Macfarlane, 2012; Wikipedia, n.d.). The spatial correlation of these institutions with South Africa's regional development landscape and past racial characterization is evident. The weakly established universities are exclusively the former Bantu Universities which were created in the second half of the twentieth century (Nkondo, 2001). This article demonstrates that the university rankings are intricately correlated with the geographic locations of the former White and former Bantu Universities in South Africa. Hence, Tilak (2011, p.5) proposes that "the fragile higher education system, with ... a weak base, may be one of the most important constraints to the region attaining high levels of socio-economic development". Given the significance of knowledge and research to regional development, this article concludes that Limpopo and Eastern Cape Province as well as Northern Cape and Mpumalanga Province, which are in the process of establishing their first universities, will continue to lag behind Western Cape, Gauteng, KwaZulu-Natal, Free State and North West Province. The next section draws from Youtie and Shapira (2008) and Marginson's (2010) theorizations of universities as public utilities that evolve into knowledge hubs to establish "learning regions" through "boundary-spanning" functions that impact on regional development in order to create a theoretical template for testing the spatial concomitance of South Africa's former Bantu Universities with regional poverty.

\section{Globalization and Marketization of Higher Education and Research: Universities as Public Utilities and Knowledge as Public Good?}

Despite the buzz about globalization and marketization of higher education, research and knowledge, governments across the world have not legislated themselves "out of higher education altogether" (Marginson, 2010, p.6966). Instead, the ascendency of knowledge-driven global economic competition has magnified policy interest in higher education research and knowledge generation (Bramwell and Wolfe, 2008; Hong, 2008; Knievel and Sheridan-Rabideau, 2009; Marginson, 2010). As Tilak (2011, p.29) puts it:

"As a bottom-line, it may be noted that public financing of higher education is still the best and most prevalent method of developing strong and vibrant higher education systems. All other sources of funds are only supplementary".

Notwithstanding continued public subsidization, higher education institutions' generation of knowledge remains relatively global, with exposure to market dynamics; however, it is not driven by free trade and market competition (Hong, 2008; Marginson, 2010; Tilak, 2011). But evidence shows that regions that are decoupled from globally-networked economy consist of low-density higher education, whilst the converse is true for globally-embedded regions (Hong, 2008; Marginson, 2010). However, the development impact between universities and geographic location is mutual and complex.

\subsection{Knowledge as Public Good}

Marginson (2010, p.6969) contents that "knowledge constitutes public goods in the technical economic sense", and it is "non-rivalrous and non-excludable" because it "can be consumed by any number of people without being depleted" and "cannot be confined to individual buyers". Basic research knowledge is virtually pure global public good that accords advantage to knowledge-driven economy through its transformative agenda (Bramwell and Wolfe, 2008; Hong, 2008; Knievel and Sheridan-Rabideau, 2009; Marginson, 2010). Global exchange and cooperation on higher education basic research knowledge is virtually free and openly accessible, except for nominal administrative charges (Marginson and Rhoades, 2002 cited in Marginson, 2010). In fact, it is the widest global exchange that optimizes the value of basic research knowledge (Bramwell and Wolfe, 2008; Hong, 2008; Knievel and Sheridan-Rabideau, 2009; Marginson, 2010). Ironically, as Marginson (2010, p.6978) puts it, the ubiquitous growth of the transformative agenda is intricately associated with uneven and partly reciprocal "global flows of people, ideas, knowledge, messages, technologies and capital. The same is true for the spatial concomitance of universities with regional development. In practice, states have 
actively participated in perpetuating spatial structures of strong concentrations of knowledge power, effective synergies with industry and attraction of talented researchers (Knievel and Sheridan-Rabideau, 2009; Marginson, 2010). Hence, globalization of higher education research knowledge involves "indigenization", wherein foreign culture is incorporated into indigenous cultures, simultaneously with "normalization and standardization" to the global (Xiaoming and Haitao, 2000 cited in Marginson, 2010). That is, the application of knowledge, a global public good, is local; however, regional development requires the establishment of "intelligent" ("learning") regions with universities and networks of research institutions that perform "boundary-spanning" functions. State activism is imperative for successful establishment of "learning" regions. Do South Africa's former Bantu Universities have the capacity to establish such "learning regions", under state capitalism?

\subsection{State Capitalism, Corporatization of Universities and Modes of Evolution}

Under the new public management approach, public utilities are steered at "arm's length" and encouraged to embark on independent fund-raising in order gain increased autonomy (Marginson, 2010; Glemarec and Puppim de Oliveira, 2012). Whereas partly deregulated, higher education systems continue to be dominated by state funding as public utilities (Altbach and Levy 2006; Bramwell and Wolfe, 2008; Knievel and Sheridan-Rabideau, 2009; Tilak, 2011). Whereas the market is not trusted in the funding of basic research knowledge generation, state capitalism governance provides that the visible hand of the state supplements the invisible hand of the market (Glemarec and Puppim de Oliveira, 2012). Equally, the regional development impact of universities requires state supplementation, which is tenuous under state capitalism governance.

It is accepted wisdom that linear models of knowledge transfer wherein segmented research commercialization process with fewer boundary-spanning institutions create innovation, is unrealistic. Youtie and Shapira (2008, p.1191) show that "current models portray technology transfer as a more complex and iterative activity, involving feedback loops across multiple dimensions", requiring universities to evolve into institutions capable of taking "more panoptic" views and performing "discursive networking functions across boundaries". Shapira and Youtie (2004) and Youtie and Shapira (2008) identify three modes of university evolution, viz.: storehouse of knowledge, knowledge factory and knowledge hub. As storehouse of knowledge, medieval universities looked backwards to accumulate and profess "old knowledge", aloof from society (Youtie and Shapira, 2008). South Africa's Bantu Universities were, paradoxically, created in the second half of the twentieth century to serve as medieval storehouses of knowledge for former Bantustans. Conversely, the nineteenth century modern knowledge factory university is associated with the growth of scientific research "experimentation" and transcendence of purely academic to practical technical disciplines, with the expressed purpose of meeting the needs of industry through applied research (Mowery, Nelson, Sampat and Ziedonis, 2004; Youtie and Shapira, 2008). In this mode, the university hopes to mimic the manufacturing assembly-line production system; and, it is forward-looking and positioned as "a factory of new knowledge" (Mowery et al., 2004; Shapira and Youtie, 2004; Youtie and Shapira, 2008; Bramwell and Wolfe, 2008; Knievel and Sheridan-Rabideau, 2009). On its part, the knowledge hub involves post-modern evolution for advancement of innovation and acquisition of capabilities for regional development impacts, made possible by the extended state funding of basic research (Mowery et al., 2004; Shapira and Youtie, 2004; Youtie and Shapira, 2008; Tilak, 2011). A knowledge hub university hopes to inculcate "indigenous" regional development through nuance capabilities for innovation (Hagen, 2002; Mowery et al., 2004; Shapira and Youtie, 2004; Harrison and Leitch, 2005; Youtie and Shapira, 2008; Bramwell and Wolfe, 2008; Knievel and Sheridan-Rabideau, 2009). Such a university serves as catalyst and animator of regional socio-economic development by fostering linkages of innovation systems, interactions and spillovers, application and commercialization (Hong, 2008; Youtie and Shapira, 2008). The "knowledge-hub" nomenclature is designed to stress the centrality of the "processes of the creation, acquisition, diffusion, and deployment of knowledge" of the post-modern university, which serves as "a boundary-spanning organization that accumulates mediating functions for the exchange of tacit as well as codified knowledge between academia and local business and financial communities" (Youtie and Shapira, 2008, pp.1188, 1189). In a democratic South Africa, former White Universities embody realistic potential to perform boundary-spanning functions.

\subsection{University as Knowledge Hub and Boundary-spanning Institution}

As knowledge hub and boundary-spanning institution, a university goes beyond the formal codified knowledge to embrace development and transference of tacit, person-embodied knowledge (Mowery et al., 2004; Shapira and Youtie, 2004; Youtie and Shapira, 2008; Marginson, 2010). The interrelationships between tacit and codified knowledge is complex because "using codified knowledge will invariably require related tacit knowledge", whilst "accumulations and 
applications of tacit knowledge, particularly those related to science and technology, invariably draw on codified knowledge" (Youtie and Shapira, 2008, p.1190). Given that codified knowledge is global public good, tacit knowledge is critical for providing competitive advantage to regional industry and business. Application of tacit knowledge requires supplementation with appropriate strategies for operationalization. Hence, the online technologies facilitating global exchange of codified knowledge cannot replace the value of face-to-face interactions between star research scientists, students and industry, because tacit knowledge "confers context-based and hard-to-replicate capabilities" to organization(s) in a geographic regional setting (Youtie and Shapira, 2008, p.1190). Region-specific strategies should attract and nurture the necessary human capital and talent for tacit knowledge transfers and industry-applications (Gertler, 2003; Mowery et al., 2004; Shapira and Youtie, 2004; Youtie and Shapira, 2008; Marginson, 2010). A knowledge hub would, therefore, facilitate value-added exchange of knowledge by creating and accumulating "boundary-spanning" functions among "the multiple sectors and actors operating in economic, governmental, educational and community spheres" (Youtie and Shapira, 2008, p.1191). A knowledge hub creates the opportunity for academic leaders, star research scientists, industry executives and heads of government agencies to serve as boundary spanners for the distribution, transformation, commercialization and application of research knowledge for continued innovation and regional development.

\subsection{Universities in Regional Development}

Governments across the world, especially those of developed nations, have increasingly imposed new expectations about the performance and contribution of universities towards regional development. South Africa is running an overwhelmingly large public university system, heavily funding both research and teaching; therefore, increasingly requiring universities to foster innovation and regional economic development. State efforts to leverage higher education institutions, especially universities, for regional development was heightened in the 1990s; and, research on the role of universities in economic development too has emphasized the significance of the regional context (Mowery et al., 2004; Shapira and Youtie, 2004; Bramwell and Wolfe, 2008; Youtie and Shapira, 2008; Knievel and Sheridan-Rabideau, 2009; Marginson, 2010). The emerging trend in Europe, USA, Japan and other advanced economies as well as in China and India show that governments are increasingly promoting "the linkages of universities to technology transfer, innovation and local development" (Shapira and Youtie, 2004; Bramwell and Wolfe, 2008; Youtie and Shapira, 2008; Knievel and Sheridan-Rabideau, 2009). Equally, the Massachusetts Institute of Technology and Stanford University, both private institutions, are examples of recipients of significant public R\&D funding. Whereas codified knowledge is global public good, "differences in national power inevitably result in inequalities" as well as the divergence of approaches to exploiting universities to promote knowledge-based regional development, shape the uneven spatial geometry of the mutual development impacts (Xiaoming and Haitao, 2000 cited in Marginson, 2010).

The notion of globalization as national "disembeddedness" and global "embeddedness" remains contestable because it is founded on a simplistic assumption about development and regionalism dynamics (Youtie and Shapira, 2008; Marginson, 2010). However, inadequate regulatory regimes allow public-funded higher education institutions to operate like private multinational entities on the global stage, with national "disembeddedness" complicity (Marginson, 2010; Glemarec and Puppim de Oliveira, 2012). Higher education research knowledge is simultaneously global, national and local because it is everywhere "nested in national government" and "shaped by patterns of social investment", with much decision-making controlled by the state or framed through national public interests (Marginson, 2010). Inevitably, university knowledge generation remains equally sensitive to national interests, without global "disembeddedness" (Mowery et al., 2004; Shapira and Youtie, 2004; Youtie and Shapira, 2008; Marginson, 2010). Importantly, states have increasingly emphasized and supported universities' regional development roles, in the hope of fostering their integration into the regional contexts to create opportunities for cultural diversity and political democracy beyond high-technology global innovations. According to Youtie and Shapira (2008, p.1191), universities "can have multidimensional impacts" on regional economies "through research and knowledge creation, education and human capital formation, know-how transfer to improve existing industry, technological innovation to commercialize and spinoff technologies, infrastructure development, knowledge-flow improvements, leadership to address regional problems, and the creation of a favourable regional milieu", notwithstanding their globalization and marketization. Universities are multifaceted regional economic actors that produce both explicit codified and tacit knowledge and human capital by actively participating in the establishment and sustenance of local networks, flows of knowledge and linkages with the "global other" (Bramwell and Wolfe, 2008). This role is, however, context-specific, varied and complex within the knowledge-based economy (Goldstein and Renault, 2004; Bramwell and Wolfe, 2008). The specific geographic, socio-economic and political contexts determine the capability and form of universities' regional development impacts. 
Beyond technical know-how, the precise contribution of universities is a function of their interactions with and responses to the needs and interests of local industry, proper alignment of knowledge assets with the multifaceted needs of local firms as well as regional interests and industry clusters across a broad spectrum (Doutriaux, 2003; Bramwell and Wolfe, 2008; Knievel and Sheridan-Rabideau, 2009). Whereas empirical evidence suggests that "all high-tech regional economies are anchored by a research university", "the presence of a strong research university in itself is no guarantee of regional economic growth" because knowledge commercialization devoid of "appropriate macro-institutional support and micro-institutional, or university level, flexibility" would make for problematic and lacklustre experience (Bramwell and Wolfe, 2008, pp.1178, 1185). Thus, questions of state institutional provisions and university self-selection policies should be intricately bound with analyses of the role of former Bantu Universities in regional development and capacity to establish "learning" regions.

The present global "society of reflexivity", which is characterized by apparent recovery of "individual subjectivity", "radical difference, diversity and personalization" (Kalantzis and Cope, 2006, p.406; Knievel and Sheridan-Rabideau, 2009, p.31), situates universities' regional development impacts within the contexts of cultural and political diversity. Previously, the iteration of mass-production-driven globalization, wherein the "agency of the few habitually dominates the agency of the many", enforced standardization and homogenization, establishing sameness and "production by command" as the hallmarks (Kalantzis and Cope, 2006, p.406; Knievel and Sheridan-Rabideau, 2009, p.31). Under such circumstances, a knowledge hub would have failed to bear culturally-appropriate regional development impacts. Along with the recovery of individuated agency, "customization and self-programmed, mediated realities" (Kalantzis and Cope, 2006; Marginson, 2010; Knievel and Sheridan-Rabideau, 2009) created the opportunity for region-specific development impacts of research knowledge. Universities have, in recent years, been pressured to supplement their traditional role of conducting basic research with explicitly applied research activities as "a measurable economic return" on public investments (Bramwell and Wolfe, 2008, p.1176). However, transformation of basic scientific research into commercial products has never been mechanistic (Bramwell and Wolfe, 2008; Youtie and Shapira, 2008; Marginson, 2010). Hence, universities have to "both remain legible to ... various stakeholders and become responsive to a pervasive rhetoric of innovation and entrepreneurship" (Knievel and Sheridan-Rabideau, 2009, p.36). To establish an "intelligent" region, a university should virtually (re)invent itself as "a better place to live" in and "a rich environment for personal growth, cultural depth, intellectual leadership, and economic development" (Knievel and Sheridan-Rabideau, 2009, p.27). Bramwell and Wolfe (2008, p.1177) describe six of the multiple ways in which a university could contribute to local industry development and expansion, thus: (a) "provision of skilled graduates who become key players in local industry"; (b) conduct "long-term fundamental research that contributes to the science base and understanding available to private firms"; (c) "promotion of an atmosphere of intellectual diversity that tolerates different approaches to the solution of technical problems"; (d) "direct collaboration with industry both on specific projects and in longer term relationships"; (e) serve as "tests beds for new technologies and research instrumentation that are ultimately transferred to industry"; and (f), becoming "nuclei for startup companies that spin-off to become the seeds of new business". These modalities provide for the possibilities of establishing a "learning" region with "boundary-spanning" functions.

\section{University as Knowledge Hub for Creation of "Learning Region"}

Universities' roles in societal change evolve gradually over time (Youtie and Shapira, 2008; Marginson, 2010). Accordingly, institutions are continuously "positioned" and "position-taking" within the global higher education landscape largely because of "their inherited geographies, histories, economies, polities and cultures, including their education and research systems" (Bourdieu, 1993 cited in Marginson, 2010, p.6971). This notion of positioned and position-taking is in accord with the modes of evolution of universities as proposed by Shapira and Youtie (2004) and Youtie and Shapira (2008). The global higher education landscape is in a state of flux, qualifying to be defined as "a relational landscape" of "a continually changing network of national systems and of individual institutions" (Marginson, 2010, p.6972). The multiple forces that influence the transition and evolution in university roles include the shift in advanced economies from "traditional mass production and linear transfer relationships to post-industrial, knowledge-driven, open, and more interactive innovation systems" (Youtie and Shapira, 2008, p.1189). This shift creates the possibility for university selfselection and self-determination. Whereas most universities across the world have evolved from being clerical and elitist, positioned above society, to being suppliers of inputs and outputs as well as technology developers, only a few have transformed into integrated institutions in an "intelligent" region promoting indigenous development and new capabilities (Shapira and Youtie, 2004; Harrison and Leitch, 2005; Youtie and Shapira, 2008). The capacity of university to evolve is dependent on its ability to reorganize research, to evolve educational missions and methods that meet the nuance qualities of human capital development for industry (Youtie and Shapira, 2008; Marginson, 2010). 
The potential of universities to position and for position-making in the global higher education landscape is shaped by at least ten elements, seven and three of which are capacity and strategy related, respectively (Marginson, 2010). Whereas five of capacity elements are open to policy intervention, two are givens; and, all the three strategy elements are open to self-determining change. The two capacity elements that are givens, which are history, and geography and scale, are important to the evaluation of the concomitance of universities and regional development in South Africa. The five capacity elements that are open to policy intervention include: material resources, global language power, knowledge power, knowledge economy concentrations, and global engagement or agency (Marginson, 2010). Basically, to transform a university into a knowledge hub the strategic project should be intricately intertwined with "boundary-spanning roles that mediate among academic, educational entrepreneurial, venture capital, industrial, and public spheres" (Youtie and Shapira, 2008, p.1188). But history and geography are the most critical determinant of the university's capacity to evolve into a knowledge hub and to create a "learning region", especially for South Africa, given the enduring apartheid legacies.

History refers to "the inherited educational traditions, language and culture distinctive to each" nation and institution (Marginson, 2010, p.6972). Whereas smaller nations have developed effective global strategies, location and size constitute advantages. Universities in smaller communities have lacked "the critical mass of industry to absorb university research outputs" (Youtie and Shapira, 2008, p.1192). Material resources involve income, investment and assets allocated to education and research (Marginson, 2010), but they are all suboptimal to history and geography. Even the knowledge power as research capacity "is partly shaped by history, geography and scale, partly a function of investment and of language power, and affected also by less tangible cultural factors such as the will and the freedom to create" (Marginson, 2010, p.6972). Knowledge economy concentrations, intricately linked to history and geography, refer to "effective synergies between higher education and research, government policies, industry and above all, evolving global cities" (Marginson, 2010, p.6972). This variable is critically important to unpacking the correlation of university landscape with regional development in South Africa.

The question to ask is: do former Bantu Universities possess the elements of history and geography necessary for being positioned and position-making in the global higher education landscape for the establishment of "learning" regions and performance of "boundary-spanning" functions? Concern should specifically be on whether these universities have the capacity and strategy to evolve into knowledge hubs and to create "intelligent" or "learning regions". There is no intention to suggest that imbuing the attributes necessary for university evolution to knowledge hub are unproblematic because most of them are intricately dependent on the givens of history and geography. Besides, there may be deliberately resistance due to institutional inertia of the university leadership and/or academia, and the balance of public versus private interests in research and technology transfers. In the final analysis, the fundamental reasons for former Bantu Universities' challenges in the globalized higher education landscape are history of creation and geographic location.

The history of universities in South Africa is straddled with fragmentation, deep paradoxes and dilemmas of ethnic institutions, seeking to separate the development of North-Sotho, South-Sotho, Tsonga, Tswana and Venda groups from those of Coloureds, Indians, Zulus, Xhosas, English and Afrikaans ethnic populace. Inevitably, the current contexts of these universities are starkly diverse, implying that the knowledge generated is embedded in deeply varied geographic, social and institutional procedural contexts as well as scientific cultures. Their role in regional development cannot be generalized. Whereas regional development is not a lone province of universities, questions need to be asked about the role of former Bantu Universities in South Africa because they were basically established to be storehouses of knowledge and to regulate knowledge advancement for subjugation of the African majority. Given the geographic constraint to both explicit codified and tacit knowledge, "advanced regions with strong university bases will benefit more from being close to universities, while those less favoured regions will suffer more due to the shortage of local knowledge resources and the reduced extra-local knowledge support" (Hong, 2008, p.590). This article asserts that only Gauteng and Western Cape Province as well as KwaZulu-Natal and Free State Province, to a lesser extent, stand to benefit from universities' impacts on regional development. Former White Universities are exclusively located in globally-renowned cities whilst former Bantu Universities of Fort Hare, Walter Sisulu University, University of Limpopo, University of Venda and University of Zululand were deprived of the capacity to contribute to regional economic development by their establishment in geographically deprived locations of the former Bantustans' small towns of Alice, Mthatha, Sovenga, Thohoyandou and Kwadlangezwa, respectively. Application of the market ethos on university knowledge and research can be expected to perpetuate disadvantage of these former Bantu Universities, making it impossible for them to establish "learning regions" or perform "boundary-spanning" functions.

Given that economic and political transition has commonly occurred without agitating the core area, "uneven regional development has been a common problem" wherein "prosperity coexists with poverty" (Hong, 2008, p.594). According to Tilak (2011, p.4), higher education "creates attitudes, and makes possible those attitudinal changes 
necessary for the socialization of individuals, democratization of political systems and the modernization and overall transformation of societies". For this same reason, globalization and marketization of higher education research in the knowledge-economy era has been viewed with scepticism in most of Africa as strategy for "recolonization of the African mind" (Mkandawire, 2011; Ndlovu-Gatsheni, 2013). In South Africa, though, global cities such as Cape Town, Pretoria, Durban and Johannesburg have the most outstanding research networks for both sending and receiving knowledge frequently, whilst those in less-favoured regions are in perpetual catch-up mode. Whereas universities in Cape Town, Pretoria, Durban and Johannesburg have contributed to the economic development of these cities and their hinterlands, their global image and status were simultaneously built on the back of these urban polities.

\section{South Africa's Higher Education: Former Bantu Universities in Regional Development}

The system of higher education in sub-Saharan Africa consists of enduring colonial and apartheid legacies (Tilak, 2011) that have rendered the notion of self-selection a deeply paradoxical phenomenon as decisions about the establishment and geographic location of universities made ethnicity and race a destiny (Nkondo, 2001). According to Tilak (2011, p.6), the weakly established institutions of higher education is explicable through three factors: colonial rule, World Bank's past policy against expansion and public financing of higher education, and the myopic national policies on higher education. Since 2003, government embarked on a process of restructuring the higher education system (South Africa.info, 2014), largely conspicuous by the creation of mergers (Answers Africa, 2014). Tilak (2011, p.5) insinuates that "the fragile higher education system, with ... a weak base, may be one of the most important constraints to the region attaining high levels of socio-economic development". Prior to 1948, the universities in South Africa were in principle not racially segregated beyond having the Afrikaans and English language divides and the University of South Africa variant which used both languages. Whereas access for Blacks was severely limited, the pre-1948 universities did not make race and ethnicity a destiny. Post-1948, separate development policy entailed formalization of the discriminatory higher education system; and, in 1959 the establishment of "a series of new universities individually ear-marked for specific racial and ethnic groupings" was legislated (Fedderke, de Kadt and Luiz, 2003, p.380). However, interpretations of the post-1948 formalization of racial discrimination in higher education are varied. There are "discontinuist" and "continuist" interpretations of the history of South Africa's higher education institutions (Fedderke et al., 2003); and, the same is true for the 2003 restructuring.

\subsection{Higher Education and Public Funding}

South Africa has a total of 475 institutions of higher education, 23 of which are public universities, 3 private universities, 100 public technical colleges and 349 private technical colleges (Tilak, 2011). The 2003 restructuring of the higher education system has organized the 23 universities into three types, viz.: traditional (11), comprehensive (6) and universities of technology (6). Whereas the traditional universities offer theoretically-oriented qualifications, the comprehensive focus on combinations of academic and vocational qualifications whilst universities of technology offer vocationally-oriented education (South Africa.info, 2014). Public universities have a mission of spurring regional economic development, but are less likely to have localized citations of their patents than private universities and research institutions (Hegde, 2005; Youti and Shapira, 2008). Evidently, the private sector dominates the higher education landscape in South Africa, with the exception of universities, which however consists of $5 \%$ of all institutions of higher learning. Prior to that shift, the World Bank championed involvement of private sector in higher education, but South Africa's universities remained an exception from the privatization of higher education (Tiak, 2011). The World Bank's past policy discouraged universities and stressed basic education and technical colleges; unsurprisingly, South Africa's higher education private sector is stronger than the public sector (figure 1). However, the five former White Universities of Cape Town, Witwatersrand, Stellenbosch, KwaZulu-Natal and Pretoria featuring in the top 100 universities of emerging economies are unquestionably the best in South Africa (Macfarlane, 2012); and, they also feature strongly in the various world rankings of universities (Wikipedia, n.d.). 
Figure 1: Institutions of Higher Learning in South Africa, 2009

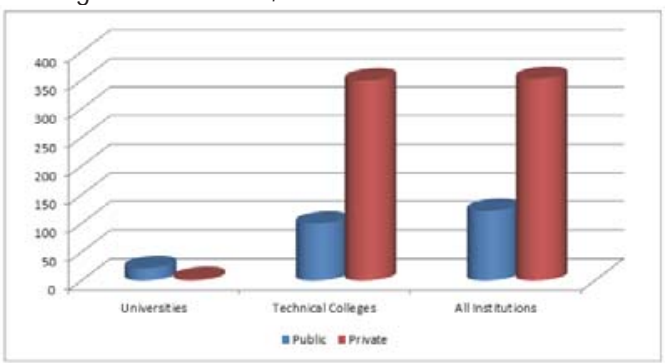

Sources: Ng'ethe, Subotzky and Afeti (2008); Tilak (2011)

Higher education in South Africa is mainly funded by the state, which was $0.6 \%$ of GDP during 2005-2008 (Tilak, 2011). This level of public expenditure was, in relation to that for the whole education system, an under-investment. Public expenditure on education in 1999/2000 and $2005-2008$ was $6.0 \%$ and $8.0 \%$, respectively, of GDP (Tilak, 2011). The under-investment in higher education is a result of the World Bank's past policy which resisted expansion and public funding thereof; and, this policy was reversed in 2008 (Tilak, 2011). But Fedderke et al., (2003) show that discrimination in the higher education in South Africa was frequently expensive, yet producing output of low quality. That is, "the investment in infrastructure and in the human capital required to start up a new set of universities was for a small student body, who were consequently funded to a disproportionately high level on a per capita basis" (Fedderke et al., 2003, p.383).

Under state capitalism, most services in the public universities, such as food, transport, housing, cleaning, security and maintenance, among others, were partly or totally privatized or outsourced (Tilak, 2011). This privatization drive has been a key feature of the former Bantu Universities, necessitated by the strife towards efficiency and saving of financial resources (Tilak, 2011). Fedderke et al., (2003, p.377) find that "discrimination in the South African tertiary education was not simply a question of under-resourcing of Black institutions" but that the low quality of output was "frequently very expensive" to attain. Therefore, the former Bantu university system "proved expensive and nasty, rather than cheap and nasty" (Fedderke et al., 2003, p.379). Fedderke et al. (2003, p.379) observe that "the university sector's experience shows that discrimination is not necessarily cheap - not only in the form of foregone development opportunities, but simply in the absolute cost of running segregated tertiary educational system". One apparent indicator of the differential quality of South African universities is evident in their contribution to the advancement of knowledge through the publication of original research (Fedderke et al., 2003, p.386). Over the years, the University of Cape Town, University of the Witwatersrand, University of Stellenbosch, University of Pretoria, University of KwaZulu-Natal and, to a lesser degree, the University of Johannesburg dominated the national research output. With the exception of the University of Johannesburg, these universities feature significantly in the 2013 edition of the QS World University Rankings (Wikipedia, n.d.). These five universities also feature in the top 100 best institutions of the emerging economies (Answers Africa, 2014; Google, 2014; Wikipedia, n.d.). The geographic locations of these and other universities are tacitly linked to the regional development landscape in South Africa.

\subsection{Geographic Location of Universities: Apartheid Legacies}

This article does not seek to repeat the history of racial division of the tertiary institution landscape in South Africa because it has been adequately addressed elsewhere (see White, 1997; Nkondo, 2001; Tilak, 2011). Instead, the purpose is to point out that in the post-apartheid society, especially since 2003, government attempted transformation of the racial landscape through mergers wherein it collapsed some former Bantu with former White Universities and Technikons. Some of these mergers have appeared to serve the intended purpose whilst others, such as the University of Limpopo, which combined the former University of the North with Medical University of Southern Africa (Medunsa), is now due for unbundling on January 01,2015 . There is evidence that suggests that mergers of former Bantu Universities have not operated as well as those between former Bantu and former White Universities. To this extent, this article concedes that a merger of former Bantu and former White Universities would have produced qualities of the latter institutions, therefore allowing for the classification of the merged institutions as former White Universities. The apartheid spatial-fix of these institutions and their racial character continues to be apparent because of their geographic distribution (table 1). 
Geographically, former Bantu Universities are exclusively located in small towns because they were established for Black people (Nkondo, 2001). These disadvantaged geographic locations have historically contributed to these institutions' incapacity to establish learning regions, especially because they do not have the necessary networks of research institutions. Conversely, former White Universities are located largely in global cities such as Cape Town, Johannesburg, Pretoria, Durban and, to a lesser extent, Bloemfontein. To this extent, former White Universities are accorded continued advantage under state capitalism in post-apartheid South Africa whilst former Bantu Universities are undermined by their geographic locations. Hence, none of the five former Bantu Universities (University of Limpopo, University of Fort Hare, University of Venda, University of Zululand, Walter Sisulu University) has established "learning regions" that can tenably be compared with those of the seven former White Universities (University of Cape Town, University of the Witwatersrand, University of Pretoria, University of Johannesburg, University of South Africa, University of KwaZulu-Natal, University of the Free State). This apartheid spatial-fix will continue to undermine the evolution of the former Bantu Universities from storehouses of knowledge, through knowledge factory modes, to knowledge hubs. Indeed, universities evolve through at least three modes and their ability to attain the transition from knowledge factory to knowledge hub is dependent on several elements of institutional and regional contexts as well as state policies (Shapira and Youti, 2004; Harrison and Leitch, 2005; Youti and Shapira, 2008). Besides, evolving into a knowledge hub would not by itself transform a university-generated knowledge into innovation and increased local and regional economic productivity, output and development. However, a university is more likely to address "the problems and opportunities of their regions if they pursue active institutional engagement to generate and share human capital, knowledge, leadership and other resources" (Youti and Shapira, 2008, p.1202).

Table 1: South Africa's post-Apartheid Universities Landscape

\begin{tabular}{|c|c|c|c|c|c|c|}
\hline \multirow[b]{2}{*}{ University } & \multirow[b]{2}{*}{ Province } & \multirow[t]{2}{*}{ City/Town } & \multirow[t]{2}{*}{ Town } & \multirow[t]{2}{*}{ Small Town } & \multicolumn{2}{|c|}{ Racial Characterization } \\
\hline & & & & & $\begin{array}{c}\text { Former } \\
\text { Bantu }\end{array}$ & $\begin{array}{c}\text { Former } \\
\text { White }\end{array}$ \\
\hline $\begin{array}{l}\text { Cape Peninsula University of Technology (former Cape and } \\
\text { Peninsula Technikons) }\end{array}$ & Western Cape & Cape Town & & & No & Yes \\
\hline $\begin{array}{l}\text { Central University of Technology (former Technikon Free State } \\
\text { and Welkom Campus of Vista University) }\end{array}$ & Free State & Bloemfontein & & & No & Yes \\
\hline $\begin{array}{l}\text { Durban University of Technology (former ML Sultan and Natal } \\
\text { Technikons) }\end{array}$ & KwaZulu-Natal & Durban & & & No & Yes \\
\hline Mangosuthu University of Technology & KwaZulu-Natal & Durban & & & Yes & No \\
\hline $\begin{array}{l}\text { Nelson Mandela Metropolitan University (former PE Technikon, } \\
\text { University of Port Elizabeth and PE Campus of Vista University) }\end{array}$ & Eastern Cape & Port Elizabeth & & & No & Yes \\
\hline $\begin{array}{l}\text { North-West University (former Potchefstroon University for } \\
\text { Christian Higher Education and University of Bophuthatswana) }\end{array}$ & North West & & Potchefstroom & & No & Yes \\
\hline Rhodes University & Eastern Cape & & Grahamstown & & No & Yes \\
\hline $\begin{array}{l}\text { Tshwane University of Technology (former Northern Gauteng, } \\
\text { North West and Pretoria Technikons) }\end{array}$ & Gauteng & Pretoria & & & No & Yes \\
\hline University of Stellenbosch & Western Cape & & Stellenbosch & & No & Yes \\
\hline University of the Free State & Free State & Bloemfontein & & & No & Yes \\
\hline University of Cape Town & Western Cape & Cape Town & & & No & Yes \\
\hline University of Fort Hare & Eastern Cape & & & Alice & Yes & No \\
\hline $\begin{array}{l}\text { University of Johannesburg (former Rand Afrikaans University, } \\
\text { Technikon Witwatersrand and Johannesburg Campus of Vista } \\
\text { University) }\end{array}$ & Gauteng & Johannesburg & & & No & Yes \\
\hline $\begin{array}{l}\text { University of KwaZulu-Natal (former Durban-Westville and Natal } \\
\text { Universities) }\end{array}$ & KwaZulu-Natal & Durban & & & No & Yes \\
\hline $\begin{array}{l}\text { University of Limpopo } \\
\text { (former University of the North and Medunsa) }\end{array}$ & Limpopo & & & Sovenga & Yes & No \\
\hline University of Pretoria & Gauteng & Pretoria & & & No & Yes \\
\hline $\begin{array}{l}\text { University of South Africa (former Technikon SA and Vista } \\
\text { University) }\end{array}$ & Gauteng & Pretoria & & & No & Yes \\
\hline University of the Western Cape & Western Cape & & Bellville & & Yes & No \\
\hline University of the Witwatersrand & Gauteng & Johannesburg & & & No & Yes \\
\hline University of Venda & Limpopo & & & Thohoyandou & Yes & No \\
\hline University of Zululand & KwaZulu-Natal & & & Kwadlangezwa & Yes & No \\
\hline Vaal University of Technology & Gauteng & & Vanderbijlpark & & No & Yes \\
\hline $\begin{array}{l}\text { Walter Sisulu University (former Border and Eastern Cape } \\
\text { Technikons and the University of the Transkei) }\end{array}$ & Eastern Cape & & & Mthatha & Yes & No \\
\hline Total & 23 & 13 & 5 & 5 & 7 & 16 \\
\hline
\end{tabular}

Source: Google, 2014 


\subsection{South Africa's Uneven Regional Development}

From a development perspective, South Africa is regarded as an emerging economy; however, poverty and inequality in this country have remained persistently severe and deep. Statistics South Africa (2014) records that in 2009 the country's poverty headcount and inequality, as measured through the gini-coefficient, were $56.8 \%$ and 0.7 , respectively. A regional perspective will however demonstrate four discernable categories in terms of poverty, which is "a key development challenge in South Africa in social, economic and political terms", according to Statssa (2014: n.p.). In terms of poverty headcount, the first category would include Western Cape and Gauteng Province where poverty rate was below 36\% in 2009, the Free State and North West Province between 61\% and 62\%, Mpumalanga, KwaZulu-Natal and Northern Cape Province between $63 \%$ and $68 \%$, and the Eastern Cape and Limpopo Province with rates between $70 \%$ and $80 \%$ (Statssa, 2014). This spatial development pattern, as captured through the poverty challenge (figure 2), is strongly correlated with the number of former Bantu Universities in the province.

With the exception of Mpumalanga and Northern Cape Province, poverty headcounts are prominent in provinces that do not host any of the five global universities (University of Cape Town, University of Pretoria, University of the Witwatersrand, University of KwaZulu-Natal, University of Stellenbosch), especially those that did not incorporate parts of the former Bantu Universities. Provinces such as KwaZulu-Natal, Free State and North West host former White Universities that merged with significant proportions of the former Bantu Universities, whereas the Eastern Cape Province hosts two former White Universities (Rhodes and Nelson Mandela Metropolitan University) and two former Bantu Universities (University of Fort Hare and Walter Sisulu University), the landscape is dominated by the latter set. Comparatively, former White Universities dominate the tertiary institutions landscape in the Western Cape and Gauteng Province, where poverty rates are $35.4 \%$ and $33 \%$, respectively, whilst the same is true for former Bantu Universities in KwaZulu-Natal, Eastern Cape and Limpopo Province where poverty headcounts are $65 \%, 70.6 \%$ and $78.9 \%$, respectively (Statssa, 2014). It should not be a coincidence that poverty rate in Gauteng Province is the least of all of South Africa and that two of the global cities of Johannesburg and Pretoria host major knowledge hubs and networks that include the University of Johannesburg, University of Pretoria, University of the Witwatersrand and the University of South Africa.

Figure 2: South Africa's Poverty Rates and post-Apartheid Universities Landscape by Province, 2009

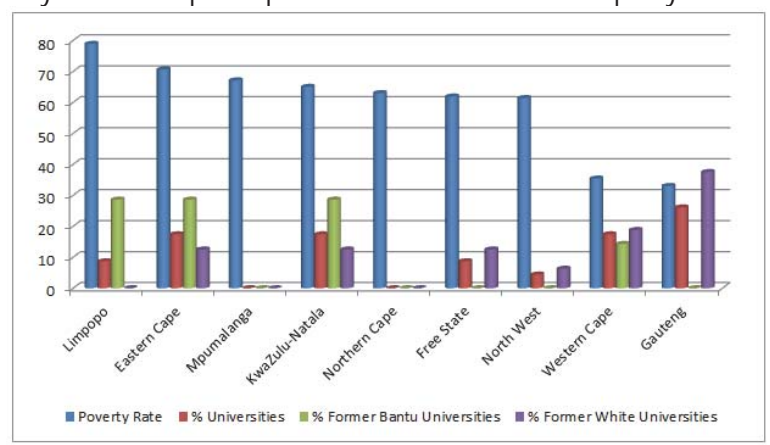

Sources: Statistics South Africa, 2014; Google, 2014

Evidently, these universities benefitted from their location simultaneously as these global cities drew from these tertiary institutions' global knowledge reach.

\section{Conclusion}

Theoretically, this article demonstrates that universities are public utilities with the potential for impacting regional development through transfers and application of tacit knowledge, conditional upon their capacity to establish "intelligent" regions and perform boundary-spanning functions. Their evolution to knowledge hub does not accord automatic capacity to establish "intelligent" regions, therefore necessitating deliberate state supplementation to build knowledge transfer networks. Whereas codified knowledge is global public good, it cannot serve the same innovative regional-contexts function as the face-to-face exchange of tacit knowledge. Hence, strong research university-base is absent in lessfavoured poor regions (Hong, 2008; Youtie and Shapira, 2008).

To the extent that universities' pursuits of evolution modes vary and are shaped by institutional and regional 
contexts, South Africa's former Bantu Universities and the geographic locations will continue to lag behind due to the prevailing circumstances that impair establishment of "intelligent" regions and performance of "boundary-spanning" roles. The former Bantu Universities are located in poor geographic regions without constellations of research institutions such as "universities, government laboratories, non-profit research organizations and private-sector R\&D entities", necessary for the creation of "intelligent" regions (Hong, 2008; Youtie and Shapira, 2008; Marginson, 2010). The odds of former Bantu Universities evolving into knowledge hubs in the absence of regional research clusters are negligible. The spatial concomitance of the former Bantu Universities and regional backwardness will continue to collude against the potential mutual development and knowledge advancement of these institutions and the provinces of their geographic location.

\section{References}

Altbach, P. and Levy, D. 2006. Private Higher Education: A global revolution. Sense Publishers, Rotterdam.

Anderson, R., Ouigley, J.M. and Wilhelmsson, M. 2009. Urbanization, productivity, and innovation: evidence from investment in higher education. Journal of Urban Economics, 66, 2-15.

Answers Africa, 2014. Top 10 Best Universities in South Africa. http://answersafrica.com/top-10-best-universities-in-south-africa-latestranking.html (Accessed: 29 June 2014).

Bramwell, A. and Wolfe, D.A. 2008. Universities and regional economic development: the entrepreneurial University of Waterloo. Research Policy, 37, 1175-1187.

Carayannis, E.G. and von Zedtwitz, M. 2005. Architechcting gloCal (global-local), real-virtual incubators networks (G-RVIN's) as catalysts and accelerators of entrepreneurship in transitioning and developing economies: lessons learned and best practices from current development and business incubation practices. Technovation, 25, 95-110.

Doutriaux, J. 2003. University-industry linkages and the development of knowledge clusters in Canada. Local Economy, 18(1), 63-79.

Fedderke, J., de Kadt, R. and Luiz, J. 2003. Capstone or deadweight? Inefficiency, duplication and inequality in South Africa's tertiary education system, 1910-93. Cambridge Journal of Economics, 27, 377-400.

Gertler, M. 2003. Tacit knowledge and the economic geography of context, or the undefinable tacitness of being (there). Journal of Economic Geography, 3, 75-99.

Glemarec, Y. and Puppim de Oliveira, J.A. 2012. The role of the visible hand of public institutions in creating a sustainable future. Public Administration and Development, 32, 200-214.

Goldstein, H.A. and Renault, C.S. 2004. Contributions of universities to regional economic development: a quasi-experimental approach. Regional Studies, 38(7), 733-746.

Google, 2014. 4International Colleges and Universities. http://www.4icu.org/za/south-african-universities.htm (Accessed: 29 June 2014).

Hagen, R. 2002. Globalization, university transformation and economic regeneration: a UK case study of public/private sector partnership. International Journal of Public Sector Management, 15(3), 204-218.

Harrison, R. and Leitch, C. 2005. Entrepreneurial learning: researching the interface between learning and the entrepreneurial context. Entrepreneurship Theory and Practice, 29(4), 351-371.

Hegde, D. 2005. Public and private universities: unequal sources of regional innovation? Economic Development Quarterly, 19(4), $373-386$.

Hong, W. 2008. Decline of the center: the decentralizing process of knowledge transfer of Chinese universities from 1985 to 2004 . Research Policy, 37, 580-595.

Kalantzis, M.S. and Cope, B. 2006. On globalisation and diversity. Computers and Composition, 23(4), $402-411$.

Knievel, M. and Sheridan-Rabideau, M.P. 2009. Articulating "Responsivity" in context: re-marking the M.A. in composition and Rhetoric for the electronic age. Computers and Composition, 26, 24-37.

Macfarlane, D. 2012. Five SA universities ranked in top 100 emerging economies list. Mail and Guardian, 01 December 2012.

Marginson, S. 2010. Higher education in the global knowledge economy. Procedia Social \& Behavioral Sciences, 2, 6962-6980.

Michalena, E. and Angeon, V. 2009. Local challenges in the promotion of renewable energy sources: the case of Crete. Energy Policy, 37, $2018-2026$.

Mkandawire, T. 2011. Running while others walk: knowledge and the challenge of Africa's development. Africa Development, 36(2), 1-36.

Mowery, D., Nelson, R., Sampat, B. and Ziedonis, A., 2004. Ivory Tower and Industrial Innovation. Stanford Business Books, Stanford, CA.

Ndlovu-Gatsheni, S.J. 2013. Why decoloniality in the $21^{\text {st }}$ century? The Thinkers, 48, $10-15$.

Nkondo, G.M. 2001. Turfloop Testimony: the Dilemmas of a Black University in South Africa. Ravan Press, Johanesburg.

Shapira, P. and Youtie, J. 2004. University-Industry Relationships: Creating and Commercializing Knowledge in Georgia, USA. Georgia Institute of Technology, Atlanta, Georgia.

South Africa.info, 2014. South Africa's Universities. http://www.southafrica.info/about/education/universities.htm (Accessed: 29 June 2014).

Statistics South Africa (Statssa), 2014. Living Conditions: Poverty. http://bet2.statssa.gov.za/?page_id=1\#provincial_gdp (Accessed: 28 June 2014).

Tilak, J.B.G. 2011. Financing higher education in Sub-Saharan Africa. Africanus, 41(2), 4-31.

White, C. 1997. From Despair to Hope: the Turfloop Experience. University of the North Press, Sovenga.

Wikipedia, n.d. Ranking of Universities in South Africa. http://en.wikipedia.org/wiki/Rankings_of_universities_in_South_Africa (Accessed: 29 June 2014).

Woodward, D., Figueiredo, O. and Guimaraes, P. 2006. Beyond the Silicon Valley: University R and D and high-technology location. Journal of Urban Economics, 60, 15-32.

Youtie, J. and Shapira, P. 2008. Building an innovation hub: a case study of the transformation of university roles in regional technological and economic development. Research Policy, 37, 1188-1204. 